\title{
A IMPORTÂNCIA DO BRINCAR NA APRENDIZA- GEM DOS ALUNOS DA EDUCAÇÃO INFANTIL
}

\section{THE IMPORTANCE OF PLAYING IN EARLY EDU- CATION STUDENTS' LEARNING}

\author{
Gabrielly Silva Ferreira ${ }^{1}$ \\ Poliana Silva Francisconi ${ }^{2}$
}

Reesumo: O tema proposto pelo artigo possuiu um interesse devido a um projeto de extensão que participei no ano de 2016. O projeto de extensão Brinquedoteca Itinerante da Pedagogia, aprovado ano passado pela comissão de pesquisa e extensão, trouxe muito interesse pela área.

O fato é que o projeto ser focado somente em trazer entretenimento para alunos de escolas públicas, nas horas vagas, conseguiu mostrar como as crianças e as escolas têm deixado de lado os jogos e brincadeiras. E resgatar esses jogos e brincadeiras, foi de muita satisfação. E o artigo, vem mostrar a importância de assimilar conteúdos teóricos, com práticas pedagógicas. De que escola, professores, alunos e pais, precisam ter interações. E que desde a educação infantil, devemos mostrar a importância de trabalhar juntos, para conseguir despertar o interesse dos alunos, e não deixar que haja uma defasagem nas escolas. Mostrar que o professor é o principal mediador de todo o

1 Graduando do $8^{\circ}$ período do curso de Licenciatura em Pedagogia da UEMG, Unidade Acadêmica de Passos.

2 Professor Me. Poliana Silva Francisconi, docente do Curso de Pedagogia da UEMG, Unidade Acadêmica de Passos

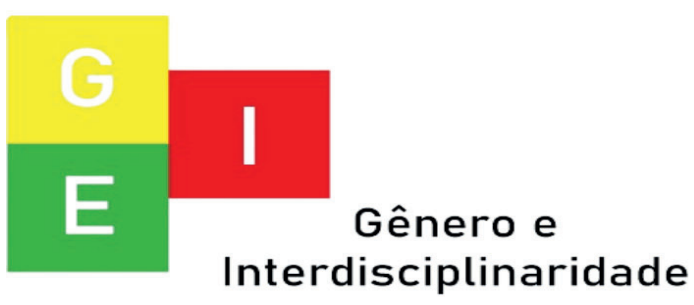


ISSN: 2675-7451

Vol. 02 - n 05 - ano 2021

Editora Acadêmica Periodicojs

processo de escolarização.

school, teachers, students and

parents need to have interactions

Palavras-chave: Educação Inwith. And that since kindergarfantil, Brincar, Prática Pedagógica. ten, we must show the importance of working together, to be able to awaken the interest of stuAbstract: The topic proposed by dents, and not let there be a gap the article was of interest due to in schools. Show that the teacher an extension project that I participated in in 2016. The extension project toyboard Toyteca Itinerante da Pedagogia, approved last year by the research and extension committee, brought a lot of interest in the area. The fact is that the project is focused only on bringing entertainment to public school students, in their spare time, it managed to show how children and schools have left games and games aside. And rescuing these games and games was very satisfying. And the article shows the importance of assimilating theoretical content with pedagogical practices. What is the main mediator of the entire schooling process.

Keywords: Early Childhood Education, Playing, Pedagogical Practice.

\section{INTRODUÇÃO}

A educação infantil tem alcançado grandes conquistas nos últimos tempos. E é de grande valia, o interesse pelo tema. Poder retratar e aprofundar os conhecimentos, além dos adquiridos no curso de graduação em Pedagogia, foi muito aproveitoso, pois mostra o real valor do pro-

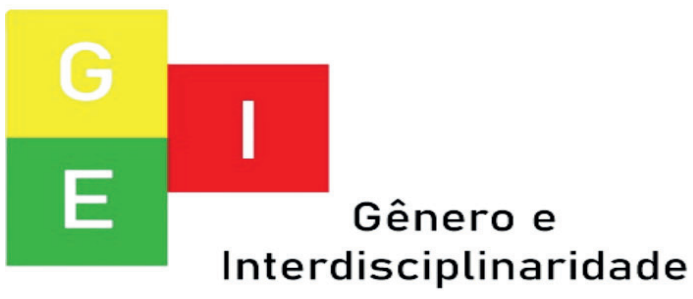


ISSN: 2675-7451

Vol. 02 - n 05 - ano 2021

Editora Acadêmica Periodicojs

fessor para os alunos pequenos.

Falar da importância do brincar na forma de ensino-aprendizagem para alunos da educação infantil, não foi complexo, mas foi emocionante. Pois muito se acha que a educação escolar, começa a ter valor somente apartir do ensino fundamental. Mas não é bem assim.

Estimular a educação com os jogos e brincadeiras, chama muito mais atenção dos alunos, do que rotulalos, a aprendizagem ditadas. Formadas por ditados, repetições, manipulações.

Nesse artigo, o primeiro capítulo, relata a contextualização historica, da educação infantil no Brasil, o porque tudo se concretizou, e de forma resumida, como se concretizou, os movimentos que idealizaram os acontecimentos.

No segundo capítulo, vamos ressaltar, a importân-

cia, de ter os jogos e brincadei-

ras implantados no cotidiano da educação infantil. Mostrar que a educação escolar, não é feita só de livros e de lousa, e sim de interações sociais.

No terceiro capítulo, define que o professor dessa área possui sua formação especifica, mas precisa estar sempre em busca de novos conhecimentos, e que o professor, é o principal ser, o mediador dos conhecimentos nessa fase da educação escolar.

$\mathrm{O}$ artigo, se conclui mostrando que precisamos revisar com bastante cautela, e aprofundar os conhecimentos mediante as situações que vivenciamos no cotidiano das escolas. Pois muito ainda tem que ser mudado, e para conseguir fazer mudanças, somente aprofundando estudos e revisando teórias, para poder montar novas leis, e deter-

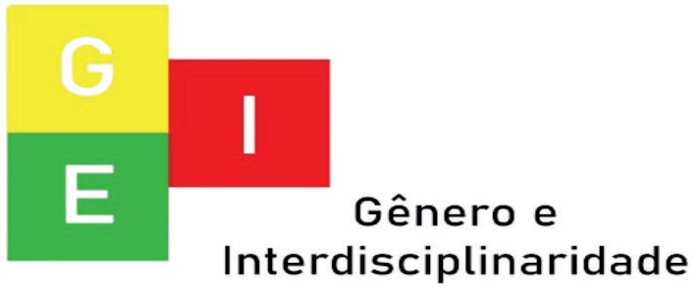


ISSN: 2675-7451

Vol. 02 - n 05 - ano 2021

Editora Acadêmica Periodicojs

mina-las, para serem seguidas e nem sempre o que acham, é o que executadas.

realmente deve ser feito, e como

Ensinar não é transfeser feito. Precisamos adquirir aurir conhecimento, mas criar as tonomia, para transpassar e repossibilidades para a sua própria ceber conhecimentos, da melhor produção ou a sua construção. forma, de como realmente vamos (FREIRE, 1996.)

aprender, entender e compreen-

E é possibilitando a proder.

dução através dos jogos e brincadeiras, que vai se adquirindo conhecimentos, construindo a vida, e mondando as histórias. Paulo Freire (1996), com o livro pedagogia da autonomia, nos mostra que somos seres capazes, de aprender e ensinar, sermos autônomos em pensamentos e criações.

E assim precisa ser as crianças, e os professores, sempre preparados para tudo, e dispostos a tudo. E o artigo, nos mostra que mesmo as leis, não sendo a realidade, não se pode deixar de medir esforços, para melhorar a educação. Para mostrar de que

\section{Desenvolvimento}

Breve contextualização da

\section{Educação Infantil no Brasil}

Os primeiros passos da história da educação infantil no Brasil, inicia-se apartir da segunda metade do século XIX, que corresponde ao período da abolição da escravatura no país. Antes disso, praticamante não existe nenhum registro de que instituições alfabetizassem crianças antes dos 6 anos de idade. (OLIVEIRA, 2011)

A partir do fim do século XIX, parte do ideario liberal,

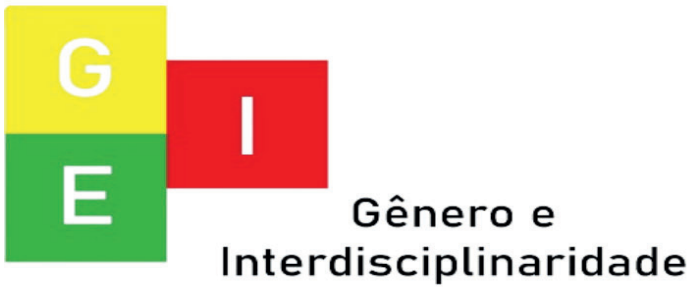


ISSN: 2675-7451

Vol. 02 - n 05 - ano 2021

Editora Acadêmica Periodicojs

reunia condições para que as elites do país, conseguissem entender quais eram os preceitos educacionais que o Movimento das Escolas Novas, tinham a oferecer. Questões que foram elaboradas no centro das transformações sociais que ocorreu na Europa e foram trazidas para o Brasil, herdando as influências americanas e europeias. E o jardim de infância, visto como um produto, uma comercialização da época, é recebido com muito entusiasmo. (OLIVEIRA, 2011)

Essa ideia de jardim de infância, no qual hoje tratamos como a educação infantil, possuia suas criticas como também seus elogios, pois muitos achavam que isso não daria certo, que o correto era mandar os filhos para fora do país quando atingissem a idade adequada para os estudos.

Mas aqueles que defen- diam, diziam acreditarem que trariam vantagens para o desenvolvimento infantil, tendo influência dos escolanovistas. Mas o auge das polêmicas era a argumentação de que os jardins de infância, tinham objetivos de caridade, atendendo assim, somente aos mais pobres, e não seria mantido pelo poder público.

No Rio de Janeiro em 1875 e em São Paulo em 1877, estavam sendo criados os primeiros jardins de infância, sendo administradas por entidades privadas. Alguns anos depois, foram sendo criados os jardins de infância público, no que se dirigia o atendimento para as crinças dos extratos soiais mais afortunados. (OLIVEIRA, 2011) Após a Exposição Pedagógica em 1885, no Rio de Janeiro, começam a aparecer posições históricas em face da educação infantil que iriam se arrastar até hoje, sendo o as-

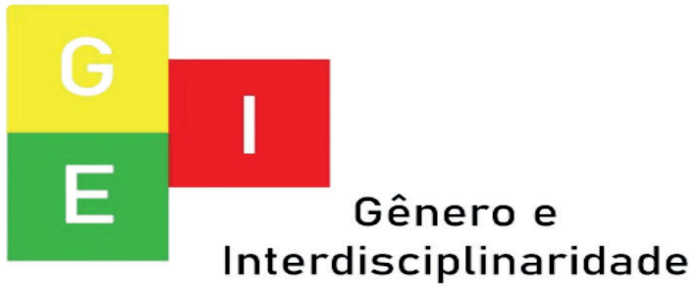


ISSN: 2675-7451

Vol. 02 - n 04 - ano 2021

Editora Acadêmica Periodicojs

sistencialismo e uma educação compensátoria aos desafortunados socialmente. Uma das maiores dificuldades da época era conseguir planejar um ambiente promotor para a educação. (OLIVEIRA, 2011)

Em 1924, educadores interessados no Movimento das Escolas Novas, fundaram a Associação Brasileira de Educação. Em 1929, Lourenço Filho publicou o livro Introdução ao estudo da Escola Nova, divulgando as novas concepções entre os educadores brasileiros. Em 1932, surgiu o Manifesto dos Pioneiros da Educação Nova, documento que defendia amplo leque de pontos. (OLIVEIRA, 2011)

A partir daqui, conseguimos observar que o poder público, começa a ter suas obrigações quanto ao valor da educação infantil, que no qual era vista somente como obrigação das empresas, para que não perdessem sua mão de obra barata, implantavam salas de amamentação, e creches, mas somente para cuidados básicos, dos filhos das empregadas.

E é através dos movimentos da época, que se dá inicio a necessidade de um ensino ativo nas salas de aula, e um ensino laico, gratuito e obrigatório. Assim, a função pública começa a ser vista. Mas não era uma conquista completa, pois as propostas educacionais seriam parte de um processo de luta pela cultura. Logo, surgiram novos jardins de infância e cursos para formar professores, mas nenhum deles eram voltado exclusivamente para o atendimento prioritário das crianças das camadas populares.

Apesar de toda luta, e de todo preparo, as creches e jardins de infância da época, não

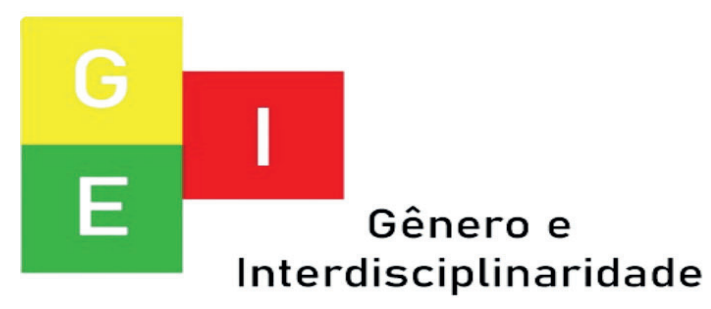


ISSN: 2675-7451

Vol. 02 - n 04 - ano 2021

Editora Acadêmica Periodicojs

estavam voltados aos preceitos escolanovistas, que é a educação infantil, já com meio de aprendizagem desde os anos iniciais da vida das crianças. Os professores estavam nesses locais somente para questões básicas, educação moral, higiênicas e aprimoramento da raça, tendo sempre como ênfase o papel da mulher cuidadora. No que se comparado as creches, e centros infantis de hoje, consideramos o maternal, mas que mesmo no nosso contexto, possui como proposito, o estimulo da motricidade, lateralidade.

Dentre muitos movimentos existentes da época, consegui entender que muito se tentou ser feito, mas muito pouco foi conquistado, como psicólogos para trabalhar o enfoque da higiene mental. Mas acima de tudo isso, o que prevalecia era planejamentos de instituições de saúde, como rotinas de triagem, lactários, ou melhor, a preocupação era com a higiene do espaço físico, multiplicando-se os convênios com as instituições filantrópicas a fim de promover o aleitamento materno e combater a mortalidade infantil.

Mas vem Vygotsky, alertando que a educação escolarizada e o professor tem um papel singular no desenvolvimento das crianças, assim identifica que a escola possibilita o contato sistemático e intenso das crianças entre si, e com os sistemas organizados de conhecimento e fornecendo a elas instrumentos para mediatizar o seu processo de desenvolvimento. (FONTANA; CRUZ. 1997).

Foi através do modo de como Vygotsky, analisava o desenvolvimento humano, que nos leva a querer discutir o papel da escolarização. (FONTANA;

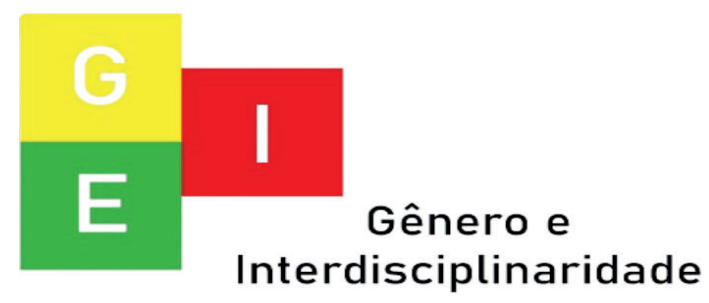


ISSN: 2675-7451

Vol. 02 - n 05 - ano 2021

Editora Acadêmica Periodicojs

CRUZ. 1997).

Mas durante a meta-

E assim, com os conhecimentos de Vygotsky, e outros psicólogos, métodos começam a ser escritos e testados, para que as crianças possam ter uma educação de qualidade, provendo de conhecimentos e desenvolvimento social. O que antes era apenas deposito de crianças para que suas mães pudessem trabalhar, se transforma em laboratórios de ciências, para conseguir entender melhor como cada criança consegui interpretar cada coisa.

E o professor, vem para ter o seu papel principal, vem como o mediador de todo o processo. Então a criança começa a entender que precisa acompanhar o professor, e o professor também a acompanhar a criança, pois terão de organizar suas ideias e separar os elementos em escalas de aprendizagem. Para chegar onde está hoje, o nosso ensino. do do século $\mathrm{XX}$, uma grande conquista foi aprovada, a Lei de Diretrizes e Bases da Educação Nacional, aprovada em 1961 (Lei 4024/61), que aprofunda a perspectiva apontada desde a criança dos jardins de infância, a sua inclusão no sistema de ensino. Assim dispunha essa lei:

Art. 23 - "a educação pré-primária destina-se aos menores de até 7 anos, e será ministrada em escolas maternais ou jardins de infância". Art. 24 - "as empresas que tenham a seu serviço mães de menores de sete anos serão estimuladas a organizar e manter, por iniciativa própria ou em cooperação com os poderes públicos, instituições de educação pré-primária". (OLIVEIRA, 2011) Assim, as creches e jar-

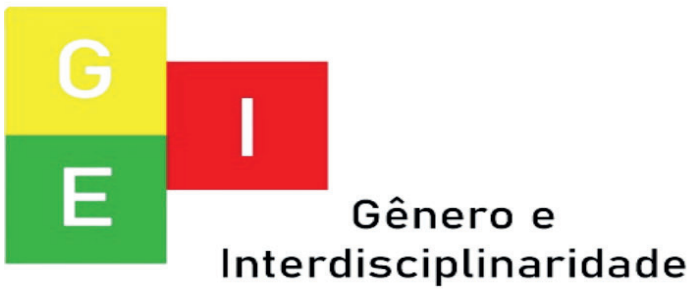


ISSN: 2675-7451

Vol. 02 - n 05 - ano 2021

Editora Acadêmica Periodicojs

dins de infância que atendiam em período integral, começam a ser procurados, não somente pelos operários, mas por todas as classes. Se analisarmos as questões atuais, as conquistas são gigantescas, pois agora é de obrigatoriedade do poder público fornecer educação básica dos 4 (quatro) aos 17 (dezessete) anos, sendo dividida em pré-escola, ensino fundamental e ensino médio. $\mathrm{E}$ a educação infantil gratuita para as crianças até os 5 (cinco) anos de idade. E não modificado, as questões que é de obrigatoriedade fornecimento da educação básica, estando incluso o oferecimento de material didático-escolar, transporte, alimentação, assistência à saúde.

Com as leis e novas resoluções pareci que tudo está melhor, que tudo tem sentido, e funciona muito bem. Mas sabemos que na realidade não acaba sendo muito o que é dito na Lei, mas acredito por mim, que ainda existem muitas conquistas que estão por vim.

Mas infelizmente ainda se consegui obeservar que por mais modernizado que tudo está, algumas questões da educação, não se modificaram, mas isso aconteci por causa da formação dos profissionais, o que acarreta está faltando profissionais qualificados e que façam isso por amor.

Não se pode mais pensar em Educação Intantil como sendo um adestramento no qual a criança fica no lugar de depositário dos conteúdos didáticos pre- estabelecidos, sem a sua efetiva participação no processo do seu próprio desenvolvimento. (AYRES, 2012.)

O que Ayres nos mostra, e alerta, é que a falta de aperfeiçoamento, de novos cursos, no-

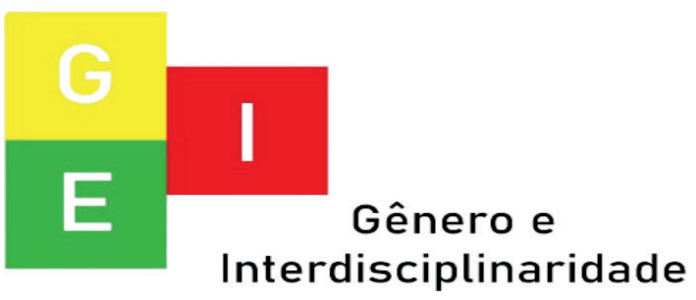


ISSN: 2675-7451

Vol. 02 - n 05 - ano 2021

Editora Acadêmica Periodicojs

vos métodos, em sala de aula e com os professores, estão ficando ultrapassados, assim, os professores com formação antiga, batem sempre o seu ensinamento na mesma tecnica e os alunos de hoje não conseguem compreender de forma esclarecedora o que está sendo passado. O que aconteci em muitos casos, o descasos dos alunos com o professor, o desenteresse pelas aulas, a falta de atenção, a conversa entre os alunos.

Então, o que vem nos dizer que é precisamos sempre estar inovando independente do meu ano de conclusão do curso de graduação, precisamos acompanhar o desenvolvimento da sociedade que os rodeia. Só assim, iremos conseguir passar ensino de qualidade, como também conseguir formar alunos capacitados e empenhados.

E focando nas práticas de educação e cuidados para as crianças pequenas, ou melhor, da educação infantil, se destinam a possibilitar a ela a integração entre os aspectos físicos, emocionais, afetivos, cognitivos-linguisticos e sociais.

Entende-se que ela é um ser completo e integro que aprende a conviver consigo mesmo, com os demais e com o ambiente, por meio de um processo gradativo e continuo nos seus contextos sociais, ambientais, culturais, suas interações sociais que lhe fornecem elementos relacionados às mais diversas linguagens e ao contato com os mais variados conhecimentos para a construção de uma identidade autônoma. (AYRES, 2012.)

Assim, concluimos que

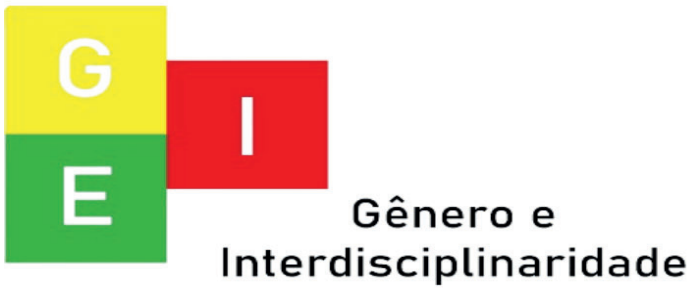


ISSN: 2675-7451

Vol. 02 - n 05 - ano 2021

Editora Acadêmica Periodicojs

tudo tem que possuir uma interação, de tudo com tudo, dos alunos com os professores, e professores com alunos, da escola com os alunos, pois tudo precisa andar junto, para que os conhecimentos sejam compartilhados, para que não haja falha de ambas as partes, para que tudo consiga ser desenvolvido como precisa. E entende-se com tudo isso, que a cada dia mais, a educação vai evoluir, a cada dia que passa, as crianças estão ficando mais espertas, e precisamos nos adaptar a elas.

O papel do brincar no processo do desenvolvimento da criança

Falar de Brincar na idade moderna, não está muito fácil, já que estamos vivendo na época que tudo gira entorno da tecnologia. Os jogos e brincadeiras de hoje em dia, estão cada vez se modernizando mais, e ficando individualizado, o que torna quase impossível socialização das crianças.

O brincar é visto somente como forma de diversão, pela maioria das pessoas, mas se esquecem que existem formas variadas de as crianças se desenvolverem tanto fisicamente, como mentalmente. Os brinquedos como os jogos possuem fins pedagógicos, que nos fazem analisar uma diversidade de situações para podermos emprega-los de modo que seja entendido como forma de ensino-aprendizagem. O que muito se escuta, é como consegui entender que brincar e educar podem andar juntos. E não só conseguem, como precisam.

Se considerarmos que a criança da pré-escola aprende de modo intuitivo, adquire noções espontâneas, em processos inte-

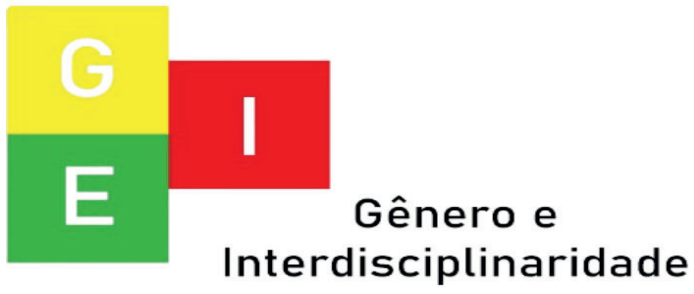


ISSN: 2675-7451

Vol. 02 - n 05 - ano 2021

Editora Acadêmica Periodicojs

rativos, envolvendo o ser humano inteiro com suas cognições, afetividade, corpo e interações sociais, o brinquedo desempenha um papel de grande relevância para desenvolvê-la. Ao permitir a ação intencional (afetividade), a construção de representações mentais (cognição), a mnipulação de objetos e desempenho de ações sensório-motoras (físico) e as trocas nas interações (social), o jogo comtempla várias formas de representação da criança ou suas múltiplas inteligências, contribuindo para a aprendizagem e o desenvolvimento infantil. (KISHIMOTO, 2011)

O educador será sempre o agente motivador e transformador, pois muitas brincadeiras vão precisar de adaptações, para serem utilizadas como fins de ensino- aprendizagem, terão que estimular as ações intencionais da criança para brincar, sendo as- sim, várias condições serão construídas para transformar aquele campo de diversão, em campo de conhecimentos, mas nunca deixando de esquecer de introduzir as propriedades lúdicas, motivadora, capacitação de ativar e impulsionar ações.

Os jogos e brincadeiras são produzidos em grandes escalas, divididos por faixas etárias, entre outras divisões, mas as que nos interessam é a classificação de lúdicas e educativas, merecendo algumas considerações, sendo:

1. Função lúdica: o brinquedo propicia diversão, prazer e até desprazer, quando escolhido voluntariamente; e

2. Função educativa: o brinquedo ensina qualquer coisa que complete o indivíduo em seu saber, seus conhecimentos

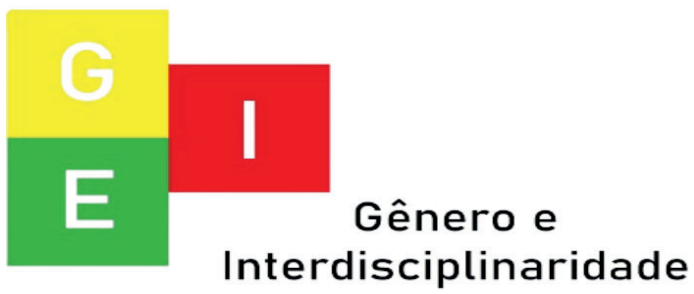


ISSN: 2675-7451

Vol. 02 - n 05 - ano 2021

Editora Acadêmica Periodicojs

e suas apreensão do mundo. (KISHIMOTO, 2011.)

Sem se dar contar a própria criança consegui potencializar seu conhecimento, vindo até mesmo de uma motivação interna, fator típico do trabalho lúdico. Mesmo com o desenvolvimento avançado das brincadeiras e dos jogos, o educar, nem sempre alcançara o objetivo desejado, mas é o primeiro passo para se conseguir aplicar com mais rigor determinado conteúdo. Mas apesar de não estar totalmente centrado e entendendo que aquela brincadeira é uma forma diferente de se passar o conteúdo, já se consegui estimular a construção do conhecimento.

Mas com tudo isso, analisamos que a reabilitação das brincadeiras e fazê-las útil na educação, o brincar foi colo- cado sob os mesmos princípios que sustentaram a ideia do novo homem: era necessário treiná-lo. Assim, o processo de pedagogização da atividade lúdica foi se tornando algo agressivo, dando origem, ainda hoje, a sistemas para utilização educacional do brincar (FRIEDMANN. p.25, 1992)

Aqui a questão já não se é vista como um passa tempo, mas sim como forma de aprendizagem, transformar aquelas aulas rígidas, em socialização, em forma de desenvolvimento intelectual, motor, sensório. Assim, novas formas de aprendizagem começam a ser elaboradas, através daquilo que é de maior interesse das crianças. Trazendo para dentro de sala de aula, o que era considerado somente distração, passando a ser conteúdo e aprendizado.

Com o decorrer da his-

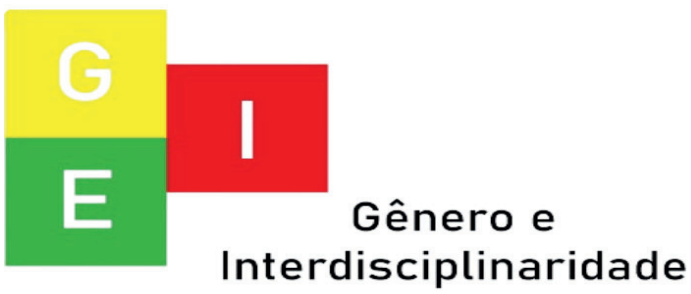


Vol. 02 - n 05 - ano 2021

Editora Acadêmica Periodicojs

tória, as formas de brincar vêm sofrendo transformações, e os destaques dessas transformações se dão por causa da industrialização, do avanço da tecnologia, assim, as interações sociais que acontecia na rua, com as brincadeiras de rua, o pular corda, a amarelinha, entre outras, ficam isoladas, e são ignoradas.

Muitas brincadeiras preservam sua estrutura inicial, outras se modificam, recebendo novos conteúdos. A força de tais brincadeiras, explica-se pelo poder da expressão oral. Enquanto manifestações livres e espontâneas da cultura popular, a brincadeira tradicional tem a função de perpetuar a cultura infantil, desenvolver formas de convivência social e permitir o prazer de brincar. Por pertencer à categoria de experiências transmitidas espontaneamente conforme motivações internas da criança, a brincadeira tradicional infantil garante a presença do lúdico, da situação imaginária. (KISHIMOTO, 2011)

Não devemos ignorar a significação da redução do espaço físico, pois hoje não se constroem casas com terreirões, não se pode brincar na rua de bola mais, pois os carros não se dão conta de que existem pedestres, e contando também que não existe mais segurança, assim os espaços que podemos considerar de lúdicos estão sendo cada vez mais ameaçados, e se tornando cada vez mais escassos.

A redução do espaço temporal, dentro das escolas, está acontecendo pelo fato de que algumas brincadeiras são julgadas como não produtivas, assim foram colocadas de lado, para que consiga enquadrar as atividades produtivas ao cotidiano das crianças. Mas isso não está

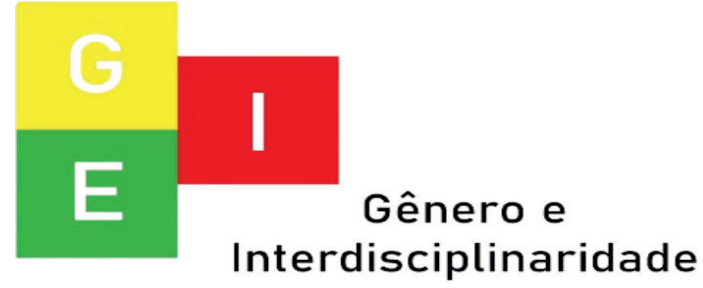


Vol. 02 - n 05 - ano 2021

Editora Acadêmica Periodicojs

acontecendo só no contexto escolar, acontece também no contexto familiar, pois hoje, a televisão ocupa grande espaço do cotidiano infantil, assim, acontece significativa diminuição do estimulo para as brincadeiras.

Brincar e desenhar são atividades fundamentais da criança. Ela brinca e desenha na rua, em casa, na escola. Pela brincadeira e pelo desenho, ela fala, pensa, elabora sentidos para o mundo, para as coisas, para as relações. Pela brincadeira, objetos e movimentos são transformados. As relações sociais em que a criança está imersa são elaboradas, revividas, compreendidas. Brincando de casinha, de escolinha, de amarelinha, as crianças se relacionam com seus companheiros, e com eles, num movimento partilhado, dá sentido às coisas da vida (FONTANA; CRUZ.1997).
A realidade que vivemos

hoje vai muito além dos nossos pensamentos, vontades e ações. Somos basicamente forçados a aderir e seguir, o que nos está nos sendo proposto. Não conseguimos ter e muito menos poder ter opinião. Devido as mudanças, e transformações, não foi somente a rotina que mudou, o que mudou acima de tudo foram as leis, e as novas exigências, o que nos impossibilita de aplicar para nossos alunos, o que achamos ser necessário, correto e melhor para eles. Não basta eu passar conteúdos, se não consigo mostrar na prática, ou melhor, como vão fazer uso desses, na sua vida, no seu cotidiano.

Os conteúdos matemáticos são os melhores exemplos para ressaltar, essa dinamização que é necessário ter com os nossos alunos. Explicar certos conteúdos, é bem mais fácil, mostrar-

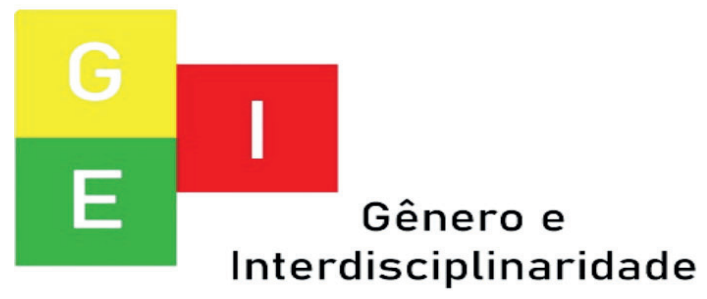


ISSN: 2675-7451

Vol. 02 - n 05 - ano 2021

Editora Acadêmica Periodicojs

mos em exemplos concretos, do que em uma simples lousa de sala de aula. Palpar a realidade dos conteúdos é muito mais fácil de memorizar, do que algo somente visual.

Dentre tudo que vivemos e convivemos, cada um vê de uma forma diferente a importância do brincar e das brincadeiras na vida e no desenvolvimento da criança, como também Piaget e Vygotsky possuem pontos de vistas distintos.

Para Piaget:

O jogo simbólico é parte de uma função fundamental do processo cognitivo da criança, a função simbólica. Essa função aparece na criança mais ou menos aos 2 anos e permite que ela possa representar uma coisa, algum objeto ou até mesmo um acontecimento, por intermédio de outra coisa, como a linguagem, o desenho, ou o gesto simbólico. (FONTANA; CRUZ.1997).

Para Vygotsky:

A brincadeira tem um papel fundamental no desenvolvimento do pensamento da criança. Ao substituir um objeto por outro, a criança opera com o significado das coisas e dá um passo importante em direção ao pensamento conceitual, que se baseia nos significados e não nos objetos. (FONTANA; CRUZ.1997).

Sendo assim, conseguimos interpretar os dois pensamentos como um complemento, pois um completa o outro, um dá a base para o outro. Tanto para Piaget como para Vygotsky, sabe-se que tem o brincar, como fonte de interpretação dos

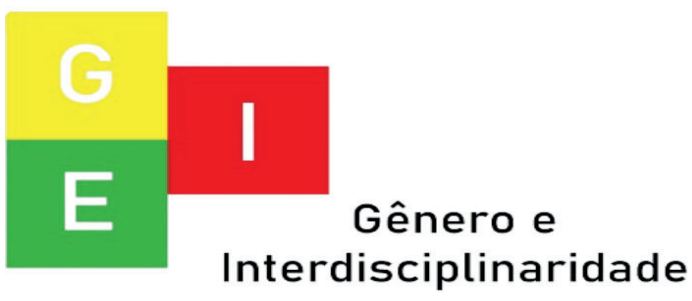


ISSN: 2675-7451

Vol. 02 - n 05 - ano 2021

Editora Acadêmica Periodicojs

acontecimentos que as crianças vivenciam. E são através dos jogos, brincadeiras, que as crianças começam a interpretar as suas dificuldades, pois elas se sentem desafiadas por ver que alguns conseguem fazer a teoria na prática, e outros não assim vêm como um incentivo, para conseguir se desenvolverem.

Ignoram-se as necessidades da criança e os incentivos que são eficazes para colocá-la em ação nunca seremos capazes de entender seu avanço de um estágio de desenvolvimento para o outro, porque todo avanço está conectado com uma mudança acentuada nas motivações, tendências e incentivos. $\mathrm{E}$ as tendências de uma criança pequena é satisfazer seus desejos imediatamente. (VIGOTSKI, 2007.)

E é mostrando a importância do brincar, a importância de trazer jogos e brincadeiras, para o cotidiano da sala de aula, que vamos conseguir resgatar alunos, mais interessados nos conteúdos, e em ir à escola. A escola vai voltar a ser o ponto de referência das crianças, que não estão se arrumando e se organizando só para aprender conteúdos maçantes, mas também dinamizar e interagir diante a esses conteúdos.

Entende-se que a brincadeira sempre terá importância na vida e no desenvolvimento da criança, sendo assim, Piaget e Vygotsky concordam que as brincadeiras sempre irão passar por um processo de transformação, de adaptação, pois cada criança consegue interpretar de uma forma diferente. Mas cada um possui um tipo de entendimento quanto ao desenvolvimento da brincadeira.

Para Piaget, essa evolução acompanha o desenvol-

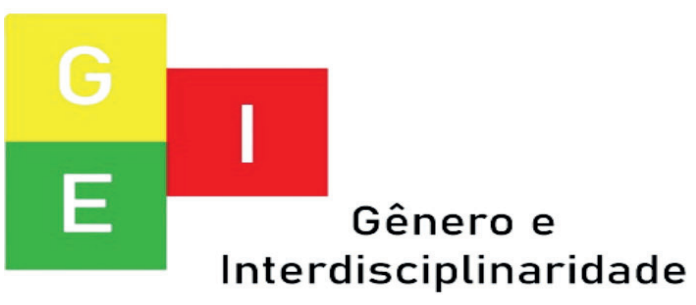


ISSN: $2675-7451$

Vol. 02 - n 05 - ano 2021

Editora Acadêmica Periodicojs

vimento da inteligência e do como impossíveis. E no fim, o pensamento, enquanto para aluno aprende se divertindo e o Vygotsky, ela se deve a mudan- professor ensina se divertindo e ça que ocorrem na interação da descontraindo, possibilitando nocriança com o meio social, em vos horizontes.

razão das diferentes posições que ocupa e das diferentes tarefas que lhe são colocadas. (FONTANA;

\section{A formação do profissional da Educação Infantil}

CRUZ.1997).

Mas independente de Muito se deve pensar inteligência ou posição social, a brincadeira sempre será importante para o desenvolvimento da criança por si só, pois é através do brincar que ela irá descobrir o mundo que a rodeia. E assim, desenvolver suas habilidades.

Sabe-se que o brincar não é somente um momento de distração, mas um momento de desenvolvimento, pois através dos jogos e brincadeiras, pode-se transmitir diversos tipos de conhecimentos, demonstrar habilidades desconhecidas, desenvolver atividades teóricas vistas sobre qual o tipo de formação um profissional da educação infantil deve ter, mas pouco se consegui entender, o porquê se passa por longos anos de estudos, para pouco se fazer. Mas afinal, esse profissional, ele é habilitado para possuir várias outras funções, basta ele escolher qual melhor ele irá se adaptar e quiser focar seus futuros estudos.

A base que se conquista com o curso de graduação em Pedagogia é muito pobre, em vistas dos outros cursos de graduação, pois estuda uma variedade

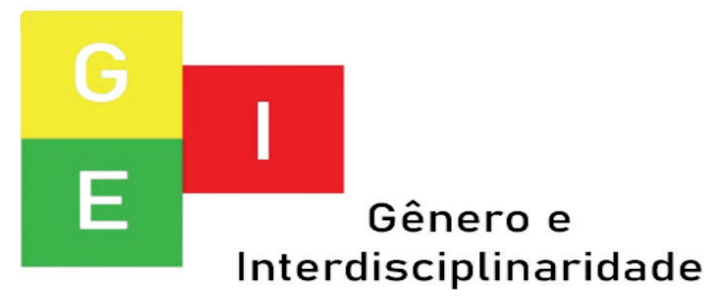


ISSN: 2675-7451

Vol. 02 - n 05 - ano 2021

Editora Acadêmica Periodicojs

de conteúdo, mas pouco se foca

em algum, de modo que consiga não somente saber fazer, e sim o como fazer.

Uma condição para o aperfeiçoamento da educação pode estar na compreensão de que a formação continuada do profissional docente se dá num encadeamento de ação e avaliação do ensinar e do aprender. Assim, é importante que o professor passe a considerar que as questões postas pela prática docente, ao invés de representarem razões para desestímulo, podem ser canalizadas para incitar a busca de soluções, e que em alguns casos, podem despertar no educador a responsabilidade com a sua auto formação. (GIESTA, 2001.)

$\mathrm{O}$ entendimento de que as práticas humanas têm essas implicações vem justificando:

A defesa do estudo do cotidiano na pesquisa educacional e a formação do pro-

fissional docente reflexivo, no sentido de permitir ao educador voltar a sentir-se mais valorizado, enxergando-se capaz de planejar e executar um trabalho educacional coerente com as ideias e teorias por ele estudadas e explicitadas, sentindo-se mais autônomo e seguro quanto ao seu saber, seu fazer, enfim, quanto a ser professor. (GIESTA, 2001.)

$O$ fato de o ensino ser rotulado, por livros didáticos, impossibilita que os professores consigam trabalhar de forma dinâmica, podendo ser o agente mediador entre os conteúdos, e os alunos. Aprendemos o que temos que falar, e fazer, mas nem sempre o como falar e fazer, e isso implicam em dificuldades na

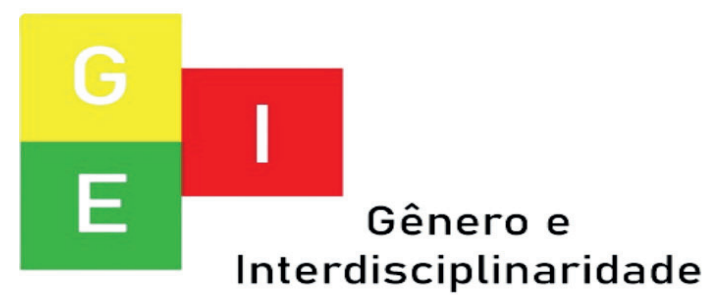


ISSN: 2675-7451

Vol. 02 - n 05 - ano 2021

Editora Acadêmica Periodicojs

sala de aula, e como trabalhar determinado conteúdo.

Os profissionais da educação infantil, que faz o curso de graduação de Pedagogia, não conseguiram distinguir, o que quer ser quando acabar seu curso superior. Pois a gama de formação que ele pode abordar é tão grande que deixa confuso, quanto ao que se deve seguir.

Analisando tudo o que é proposto, seria correto, possuir cursos específicos, com formações especificas que daria direito a aquele profissional, desde o início do curso saber o que realmente irá trabalhar em sala de aula, e o como irá trabalhar.

O desejável é que fossem proporcionadas evoluções e continuidade entre a formação inicial e aperfeiçoamento da prática pedagógica, procurando superar a justaposição de teoria e prática, diminuindo o distancia- mento entre a concepção teórica e a vivência em tempos e espaços diferentes no cotidiano escolar. Tornar-se- ia, dessa forma, mais natural e gratificante o desenvolvimento profissional do educador. (GIESTA, 2001.)

Sendo assim, como o profissional não possui uma área especifica de atuação, logo após a sua formação inicial, tem que se dar início, a algum tipo de formação continuada, sendo às vezes outro curso, que possibilite aderir conhecimentos específicos, para área que se quer trabalhar, ou pós-graduação, cursos técnicos, mestrados, cursos de especialização.

Mas iremos aprender mesmo a trabalhar no que desejamos, somente executando na prática, mesmo sem saber muito como progredir, como trabalhar. Vai ser o nosso cotidiano, o nosso querer ser e fazer, que implicará

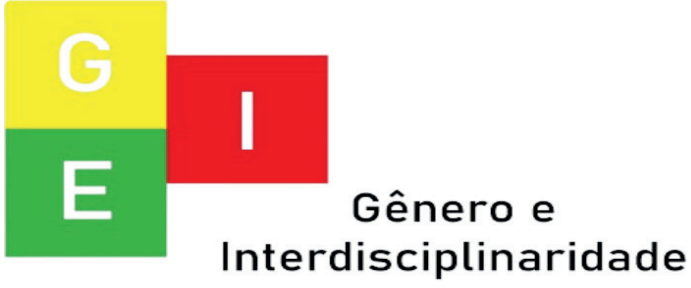


ISSN: 2675-7451

Vol. 02 - n 05 - ano 2021

Editora Acadêmica Periodicojs

no que seremos, e como seremos.

Materiais para se trabalhar determinados abordagens, encontram-se na internet, perguntando outros professores, pegando emprestados de professores antigos. Mas o fazer acontecer em sala de aula, somente o profissional que está empolgado em querer fazer acontecer, que irá conseguir.

$\mathrm{O}$ educador que, corajosa e honestamente, analisa sua prática e as respostas que dela obtém evita, também, a alienação e a apatia frente as situações emergentes da educação escolarizada e do exercício do magistério. A didática no curso de formação de professor, se incluir na abordagem de seus conteúdos o caráter investigativo e de proponente de alternativas pedagógicas, pode auxiliar atuando como elemento facilitador do entendimento do fenômeno do ensino como prática social no dia-a-dia da escola:
Em suas múltiplas determinações, procurando-se desvelar o seu relacionamento em correspondência e, ao mesmo tempo, em contradição com outras práticas na formação social brasileira (OLIVEIRA, 1993).

O profissional da educação infantil será sempre a peça principal no início da vida escolar de uma criança. Somente através das vontades dele, que consegui seguir, mesmo tendo que se rebaixar aos rótulos que se vivencia nas escolas. Pois ele é o elemento que facilita a intermediação entre os conteúdos, e a maneira como esses conteúdos tem que ser entendidas, e como esses conteúdos, vão ajudar fazer seus dias acontecerem um dia após o outro. Só esse profissional, que irá conseguir convencer de

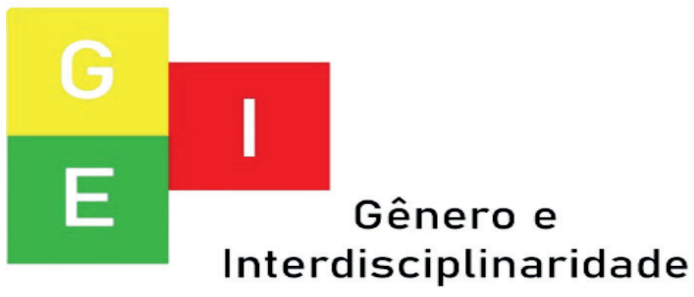


ISSN: 2675-7451

Vol. 02 - n 05 - ano 2021

Editora Acadêmica Periodicojs

que tudo isso que está sendo passado para essas crianças, pode ser utilizado de alguma forma, de modo positivo e proveitoso na vida de cada um.

É por tudo aquilo que os professores têm de precioso e de indispensável que as crianças não compreendem que eles sejam mal remunerados, desconsiderados e ás vezes, até desacreditados, porque quem luta pela paixão de transmitir conhecimento tem tanto de sábio como de aventureiro e, por isso mesmo, devia ser objeto de todos os cuidados. Porque é pela mão dos professores que o mundo se transforma em justo, aberto ao novo e à mudança, e liga curiosidade com sensatez e paixão. (SÁ, 2016.)

Para muitas crianças, os professores são os super-heróis, é quem os dá o poder do conhecimento, o ser acima de tudo. Mas nem sempre se dão conta, de que esse professor realmente faz tudo isso por amor, por paixão. A profissão que muitos alunos anseiam, mas quando atingem certa consciência desistem, por causa da baixa remuneração, são poucos que se igualam aos seus super-heróis, em busca de mudança, querendo trazer melhorias para essa profissão.

É através da inocência dos pequenos, que muitos se apaixonam pela profissão, e vão à luta, esquecendo que os pais desses alunos, desprezam o que esses professores representam para seus filhos.

As crianças admiram os professores como admiram poucas pessoas mais. E admiram a beleza com que eles as cativam, o engenho com que as estimulam e as histórias que trazem, sintetizando a sabedoria que a ciência e a técnica não conseguem decifrar. As crianças admiram os

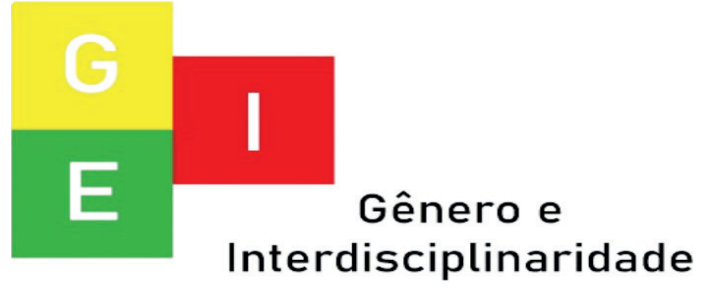


ISSN: 2675-7451

Vol. 02 - n 05 - ano 2021

Editora Acadêmica Periodicojs

professores porque sabe que admiração supõe espanto e surpresa, respeito e estima gratidão, e ainda, humildade. (SÁ, 2016.)

Por isso que esse profissional, nunca acabará, pois só eles conseguem acreditar na inocência dos seus alunos, ter paciência para conseguir interpretar suas histórias longas e repetitivas. Esse profissional pode ter pouca bagagem na sua formação inicial, mas a convivência, a vivência, faz com que ele adquira conhecimentos continuados, sempre pensando em melhorar suas aulas, em trazer seus alunos para dentro de suas salas.

As crianças reconhecem que os professores são os melhores amigos da insubmissão. Porque apesar de todos os maus-tratos, percorrem quilômetros, todos os dias, atrás de um sonho. (SÁ, 2016.) Perdem noites de sonos, pensando em como ajudar seus alunos, a entender e compreender melhor determinado conteúdo.

A articulação do ensino e da pesquisa na formação docente tem dois fortes chamamentos: o saber como se aprende e como se ensina, concretizando uma comunicação em que se estabeleça produtiva negociação de significados entre estudantes e educadores, e o outro sendo, o compreender os fundamentos do conteúdo especifico da disciplina ministrada, habilidades cognitivas, atitudes e estratégias a serem ensinadas e aprendidas para melhor atuar frente à informação veiculada em fontes variadas. (GIESTA, 2001.)

O educador, em alguns casos, na sua formação inicial constrói sua maneira de promover e produção de saberes integrada à sua formação profissional, tomando a decisão de

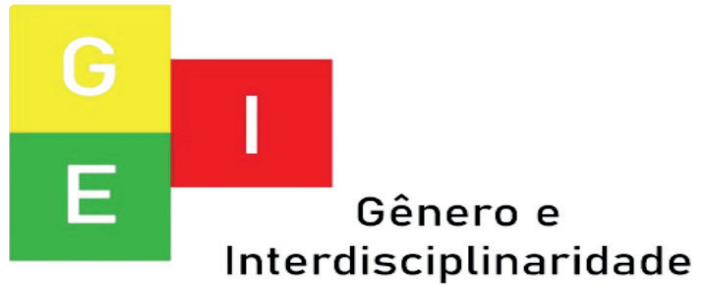


Vol. 02 - n 05 - ano 2021

Editora Acadêmica Periodicojs

tornar-se alguém que opta por aperfeiçoar constantemente seu saber e seu fazer ou por seguir a tradição de ater-se ao livro didático e a exercícios escolares desvinculados de intenções educativas que extrapolem os muros escolares. (GIESTA, 2001.)

E acima de tudo isso, o professor até pode se opor a seguir as normas rotuladas, mas de algum modo, ele sempre terá de ir à busca de novos conhecimentos, e novas didáticas, pois tudo se evolui, tudo muda até mesmo o que está escrito nos livros didáticos.

O professor, acima da sua formação profissional, sempre será o ser principal dentro de uma escola, ou outro tipo de instituição, e independente de ser formado em magistério ou graduação, o professor, que é realmente professor, faz tudo por amor, e não precisa de nenhum curso especifico, que mude seu legado.

Hoje em dia, a formação do professor de educação infantil, possui destaque, pois nos concursos públicos, não são mais aceitos a formação antiga, de magistério, e quem realmente ama o que faz, já foi em busca da sua formação maior de graduação, para não deixar seus pequenos de lado.

Ser professor, é de grande valia e responsabilidade, somente quem vive dessa realidade, sabe explicar tudo que se passa, e tudo que ainda se vai passar, e quer passar. Muitas lutas pelos direitos dos professores, estão por vim, pois sem eles nenhuma outra profissão tem bagagem e capacidade para se formar de maneira concreta.

\section{Percurso Metodológico}

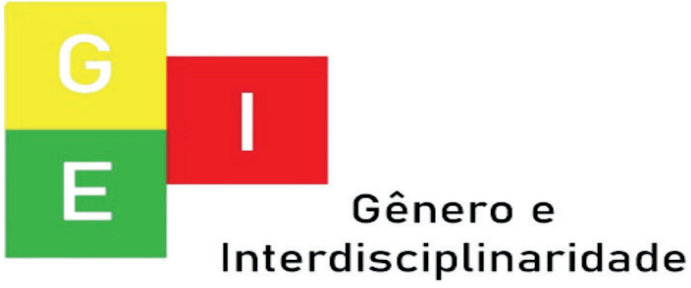


ISSN: 2675-7451

Vol. 02 - n 05 - ano 2021

Editora Acadêmica Periodicojs

Os estudos desenvolvidos neste artigo, foi baseado em recursos bibliograficos de aquisição própria. Esses recursos, foram adquirido com base nos conhecimentos por autores, como Zilma de Moraes Ramos de Oliveira, Tizuko Morchida Kishimoto, Sonia Nunes Ayres, entre outros, nos quais esses podem nos dar uma base teórica, sobre a educação infantil e as maneiras de alcançar melhores resultados, para um aprendizado de qualidade, que possibilita que os alunos avançem de nível de ensino com uma boa bagagem.

A pesquisa possui uma abordagem da pesquisa Qualitativa, tendo em vista por não utilizar uma pesquisa de campo com experiências muito concretas, não interpretando entrevistas, sendo simplesmente conhecimentos adquiridos na teória aplicada em sala de aula, fatos acon- tecidos no dia-a-dia, atráves dos estágios, e Projeto de Extensão. Mas podemos resaltar que o objeto da pesquisa qualitativa é o universo da produção humana e suas relações, representações e intencionalidades, que dificilmente pode ser traduzido em números e indicadores quantitativos, pois, de acordo com Minayo (1994, p.21):

"A pesquisa qualitativa trabalha com o universo dos significados, dos motivos, das aspirações, das crenças, dos valores, das atitudes. Esse conjunto de fenômenos humanos é entendido aqui como parte da realidade social, pois o ser humano se distingue não só por agir, mas por pensar sobre o que faz e por interpretar suas ações dentro e a partir da realidade vivida e partilhada com seus semelhantes."

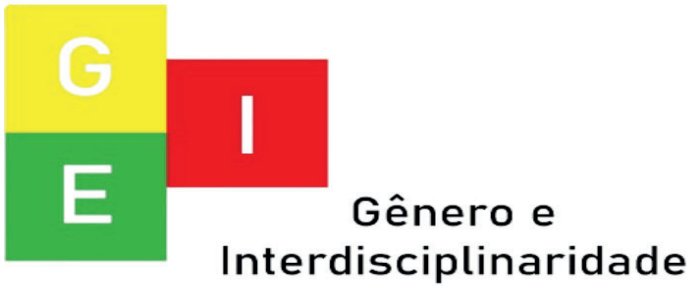


Vol. 02 - n 05 - ano 2021

Editora Acadêmica Periodicojs sa realmente ser modificado, mas

O objetivo de optar por uma pesquisa somente bibliógrafica, foi pela facilidade que encontrei ao entrar numa livraria, a quantidade de livros disponiveis, e atualizados está sendo bem grande, pois o assunto está sendo atual. Novos estudos estão acontecendo, para que possamos conseguir implantar novos métodos de ensino, e melhorar a educação desde sua base.

A base da educação, é primordial, e tem que ser muito valorizada, por isso o meu interesse pela área. Atráves do estudo, consegui ver, que muitos teóricos possuem interesse na área, e é de grande satisfação ver a busca por melhorias.

Além da pesquisa bibliógrafica, tenho intenção de ir ainda a fundo nessa pesquisa, entender o porque nada ainda foi feito concretamente, o que preci- isso me cabe, a fazer um mestrado, desenvolver pesquisas mais a fundo, e poder tratar de mudanças em orgãos que dizem respeito a isso.

\section{Considerações Finais}

Detalhar e debater assuntos a respeito da Educação Infantil, não foi nada facil. $\mathrm{O}$ assunto é extenso, e tem que ser bem detalhado. Para chegar onde tudo está hoje houve um percurso de conquistas e de desprazeres, muito grande. Pareci que quanto mais direitos se conquitava, mais deveres eram implantados, e tudo tinha sua forma de dificultar, mas isso acaba sendo fatos da atualidade ainda.

A Educação Infantil no Brasil, tem sua glória concretizada firmamente no século XXI, onde as coisas parecem começar

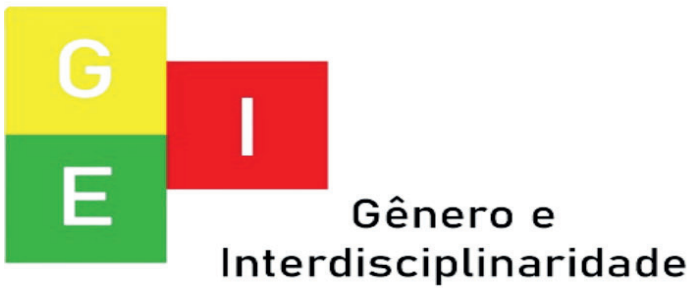


ISSN: 2675-7451

Vol. 02 - n 05 - ano 2021

Editora Acadêmica Periodicojs

a funcionar melhor fora do papel, se tornando realidade, não apenas meras palavras debatidas, escritas e isoladas depois.

Incluir a Educação Infantil como uma forma diversifidade de estudos, é bem desafiante, mas muito mais ainda gratificante, pois o trabalho feito com esses pequenos alunos, é bem reconhecido, pela forma de carinho, que essas crianças tem com os profissionais da área.

Incluir os jogos e brincadeiras nessa fase do aprendizado escolar, é algo que nós mostra o andar no futuro desses alunos, pois se quando pequenos eles são capazes de interpretar as disciplinas como uma forma de entreterimento, eles conseguiram nas fases mais avançadas dos estudos, fazerem esse tipo de assimilação, nos conteúdos mais complexos. E mostrar para esses alunos, que tudo que aprendemos, e estuda- mos no fundo possui um fundamento, deixa que eles se interressem cada vez mais pelas aulas e pelos conteúdos.

Mas infelizmente, com todas as mudanças que aconteceram, no decorrer de todas as implantações, a tendência é cada vez mais rotular os alunos a conteúdos, e discriminar o que poderia facilitar o aprendizado.

O brincar, é tratado por muitos profissionais da área, como também por intermediadores da educação, como algo inútil, o que na realidade é o oposto, e esse estudo que foi realizado, consegui mostrar, que atráves dos jogos e brincadeiras, as crianças podem aprender muito mais. Só que para isso, é preciso dar a liberdade tanto para os alunos, como também para os professores, pois eles sempre serão os mediadores do conhecimento dos alunos, e é através deles que

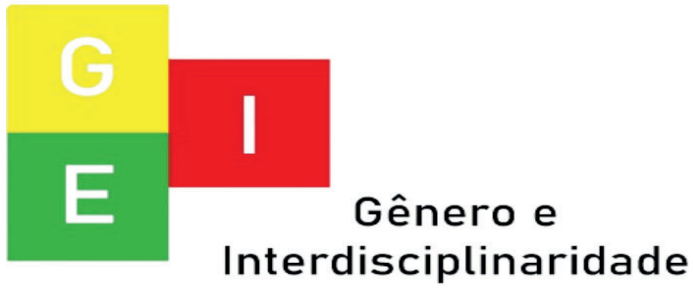


Vol. 02 - n 05 - ano 2021

Editora Acadêmica Periodicojs

todo o conteúdo será passado, de forma diversidade, e trazendo cada vez mais esses alunos para sala de aula.

Quem sabe essa defazagem dos alunos que tem acontecido muitos nas escolas, não seja culpa da rotulação de conteúdos, da falta de trabalhos mais dinâmicos, conteúdos diversificados, falta das intervenções pedagógicas mais centradas.

Tudo tem que ser muito bem analizado, muito bem estudo, e entendido, pois muitos conteúdos complexos, ficam mais compreensivos, se for trabalhado com algo concreto, e esse concreto, pode ser um jogo ou algum brinquedo que podemos construir com nossos próprios alunos.

\section{REFERÊNCIAS}

AYRES, S. N. Educação Infantil: Teorias e práticas para uma proposta pedagógica. Petrópolis:

Vozes, 2012.

FONTANA, R.; CRUZ, N. Psicologia e Trabalho Pedagógico. São Paulo: Atual, 1997.

FREIRE, P. Pedagogia da autonomia: saberes necessários à prática educativa. São Paulo: Paz e Terra, 1996.

FRIEDMANN, A. A evolução do brincar. In: FRIEDMANN, A (org.). Direito de Brincar: Brinquedoteca. 1. ed. São Paulo: Scrita: ABRINQ, 1992. (pp. 23 -31)

GIESTA, N. C. Cotidiano escolar e formação reflexiva do professor: moda ou valorização do saber docente?. 1. ed. Araraquara: JM Editora, 2001.

KISHIMOTO, T. M. O jogo e a educação infantil. In: KISHIMO-

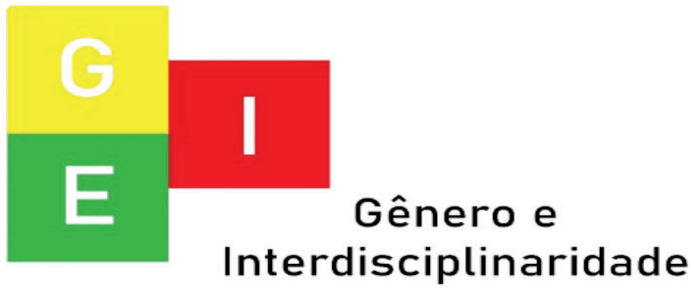


TO, T. M (org). Jogo, Brinquedo, Brincadeira e a Educação. 14. ed. São Paulo: Cortez, 2011. (pp. 15 $-48)$

MINAYO, M. C. de S. Ciência, tecnica e arte: o desafio da pesquisa social. In: MINAYO, M. C. de S (org). Pesquisa social: teória, método e criatividade. 21 . ed. Petropolis, RJ: Vozes, 1994. (pp. 9 $-29)$

OLIVEIRA, Z. DE M. R. DE. Educação Infantil: fundamentos e métodos. 7. ed. São Paulo: Cortez, 2011.

OLIVEIRA, Maria Rita N. S. A sala de aula como objeto de análise na área didática. In: OLIVEIRA, Maria Rita N. S (org). Didática: ruptura, compromisso e pesquisa. 1. ed. Campinas: $\mathrm{Pa}-$ pirus, 1993.
SÁ, E. O Ministério das crianças adverte: Brincar faz bem à saúde. Rio de Janeiro: Casa da Palavra, 2016.

VIGOTSKI, L. S. A formação social da mente. 7. ed. São Paulo:

Martins Fontes, 2007. 